\title{
De. 265
}

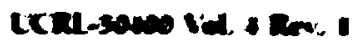

\section{Evaluated Nuclear Data Library}

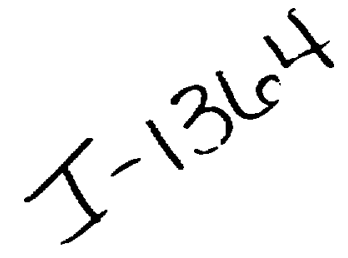

R. J. Howerton

R. E. Dye

S. T. Perkins

MASTER

October 8, 1981

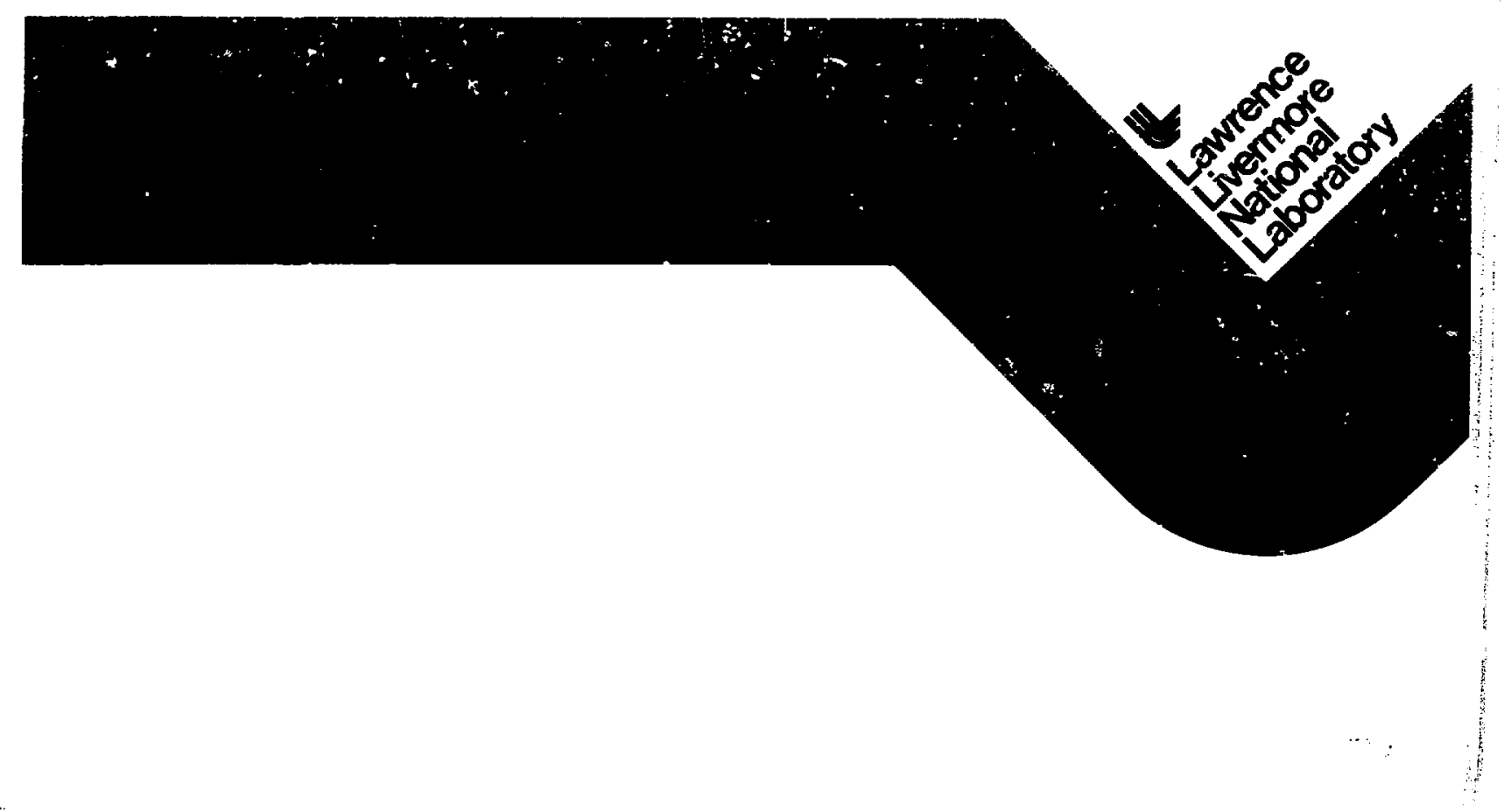




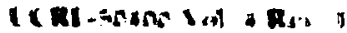

\title{
Evaluated Nuclear Data Library
}

\author{
R. J. Howerton \\ R. E. Dye \\ S. T. Perkins
}

Manuscript date: October 8, 1981

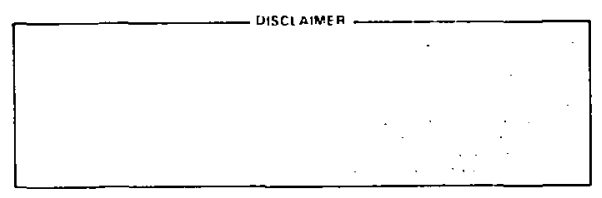

I.AWRENCE LIVERMORE LABORATORY Eniversits of Californial E Livermore, California • 94550 


\section{FORINORD}

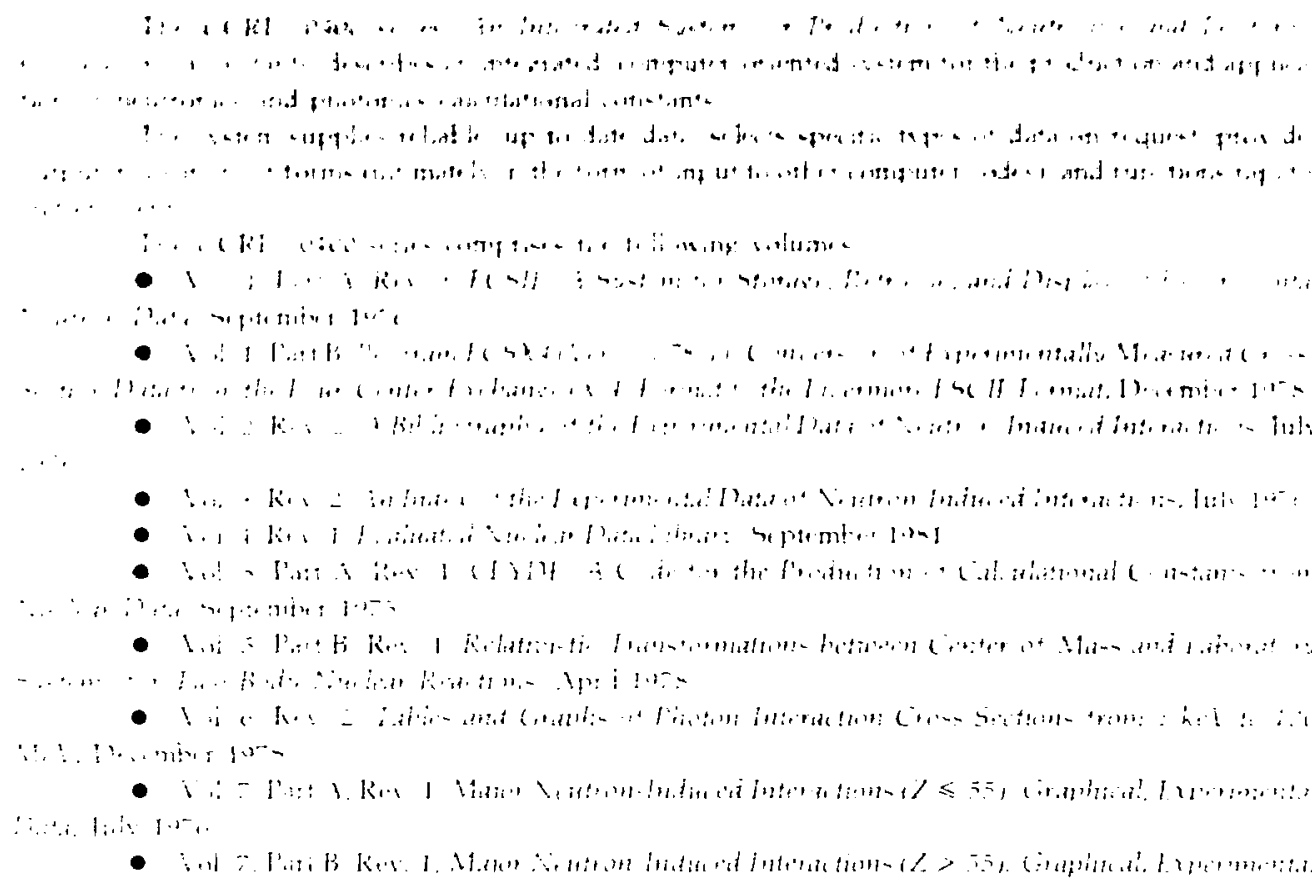

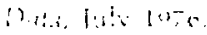

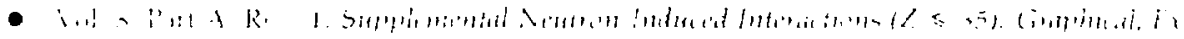

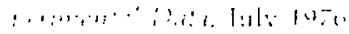

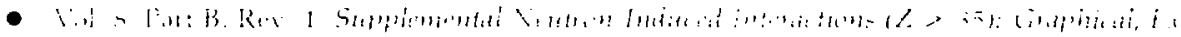

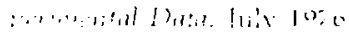

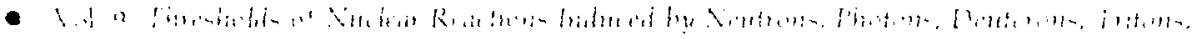
.1. 1 :

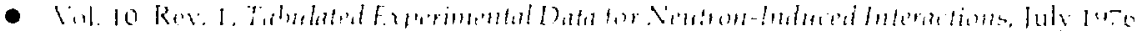

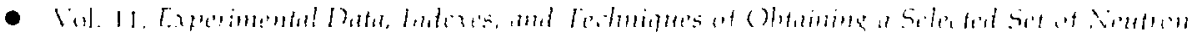

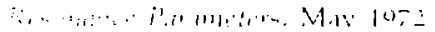

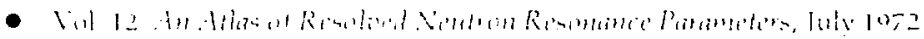

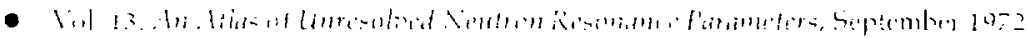

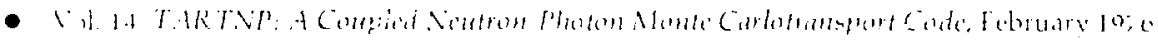

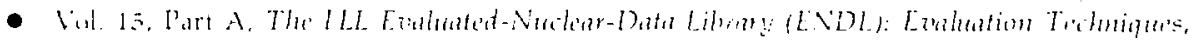

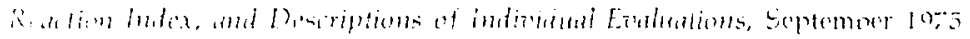

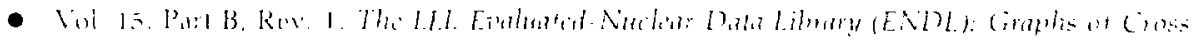

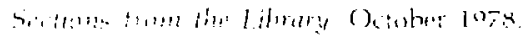

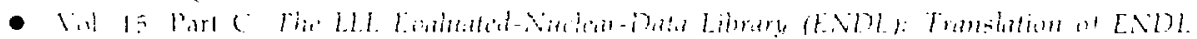

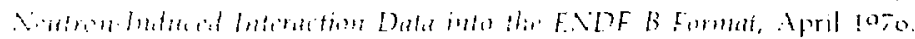

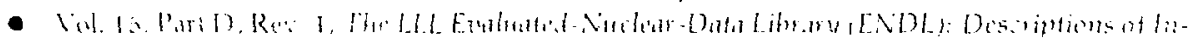

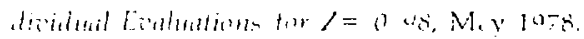

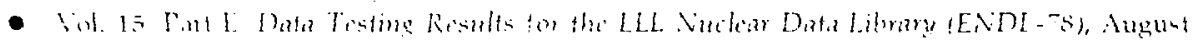
$10 \div 0$ 


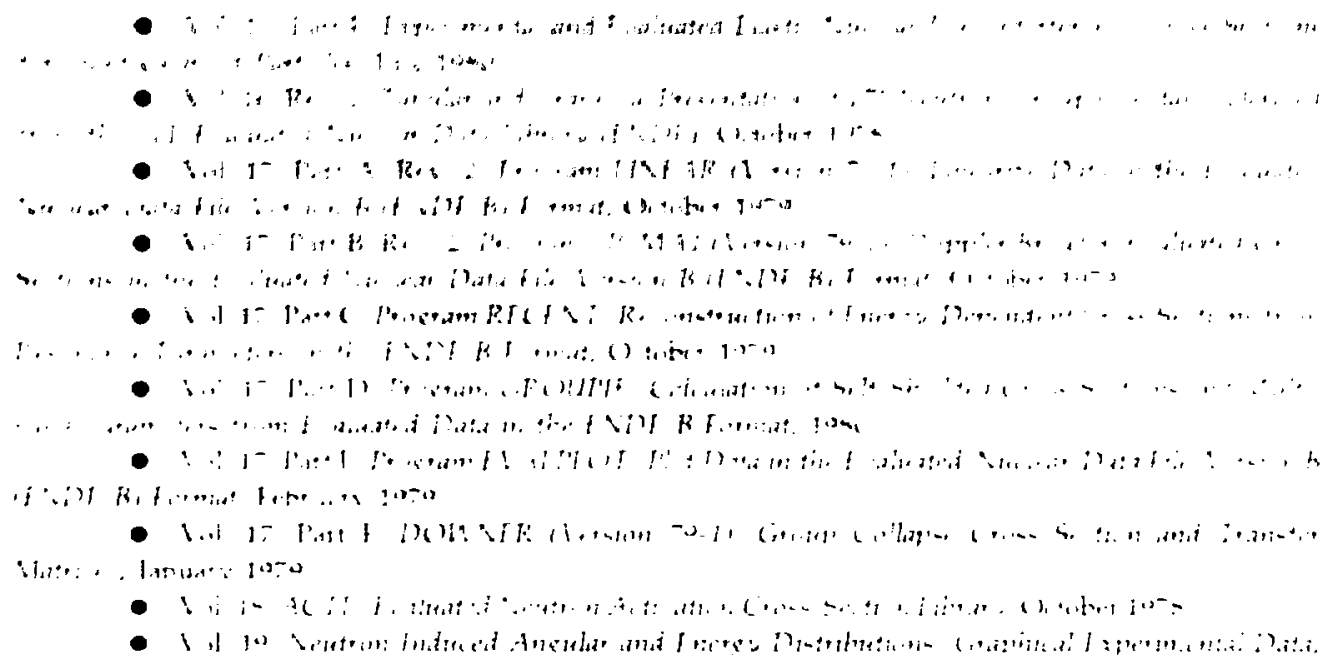

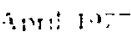

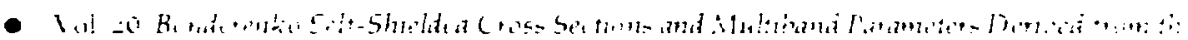

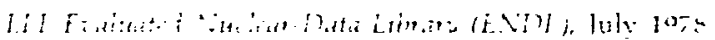

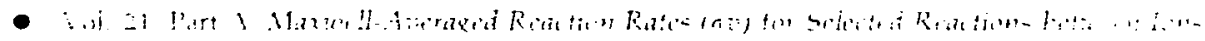

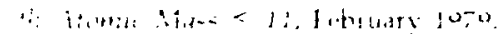

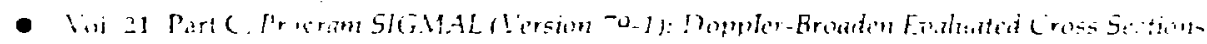

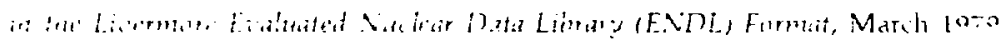

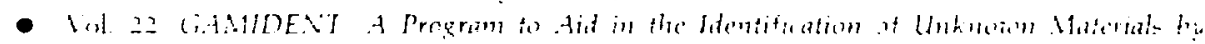

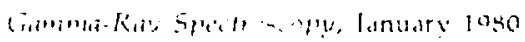

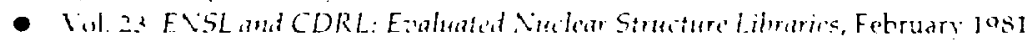

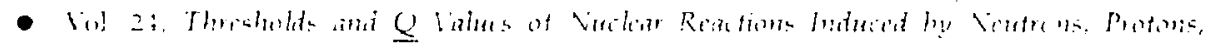

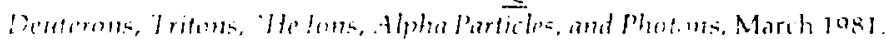




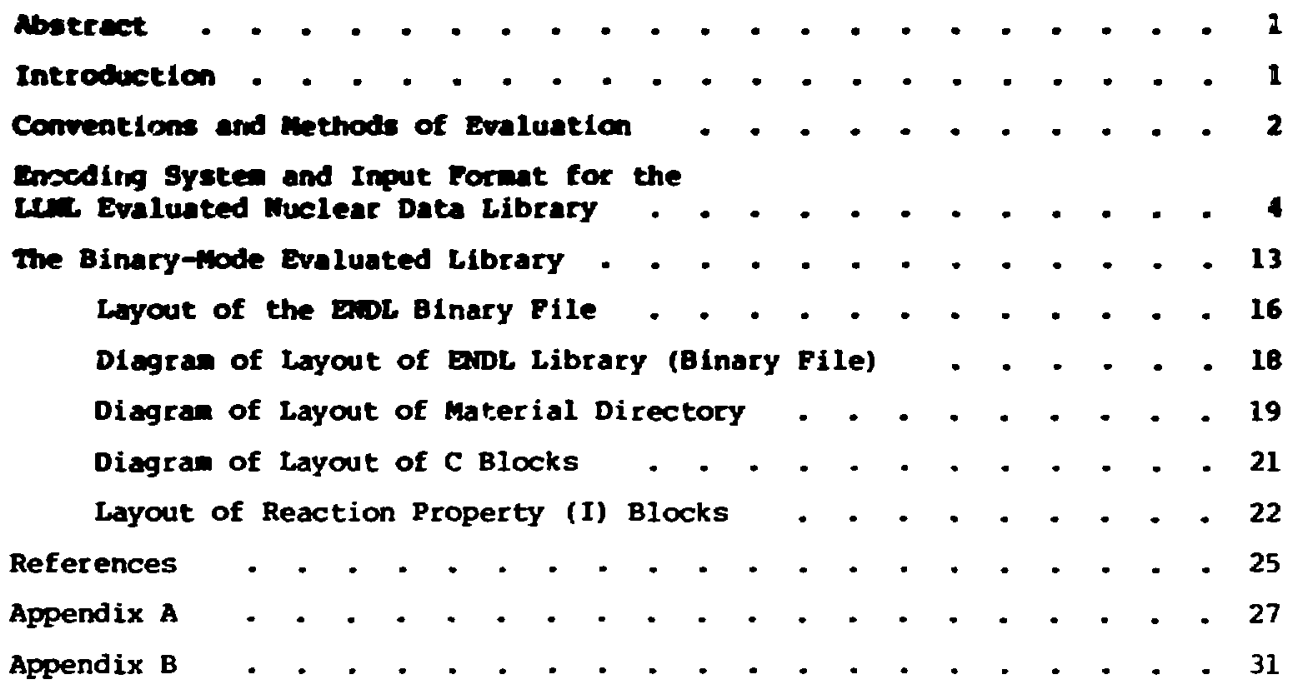




\begin{abstract}
ASSTRACT
The Lavserce Livermore ational Laboratory (LLVI) coliection of nvaluat.. J data for neutron-, photon-, and charged-particle-induced reactions is anintained in a computer-oriented systen. In this raport we rerount the history of Evaluated Nuclear Data Librarv, describe the metnods of ava!ua:ion, and give examples of input and output representation of the data.
\end{abstract}

\title{
INTRODUCTION
}

The LLNL Evaluated Iuclear Data Library nas existed since 1958, in a succession of forms and formats. In its parliest form it was a series $J E$ internal memos containing tabulations of cross sections and angular distributions for a few isotopes to be used in neutronics calculations. It was soon found that some type of mechanization should be undertaken botil inr efficiency and for convenience. Thus, in rapid succession, the library went cirough stages of punched card and punched paper-tape, and then to the first magnetic-tape BCD card image form. Of course, once the library was in one computer-readable form, it could be translated with relative ease to another computer-readable form. It is currently maintained as a CRAY-l binary-mods? File and contains data for neutron-induced reactions, photon interactions witn matter, and charged-particle-induced nuclear reactions. Ten different particles are presently defined. Yore can be addeil as needed. The data are made available on magnetic tape in a transmission format described in Appendix $A$ Those who wish to use the binary file will find its layout described in the fourth section of this report.

Plots and listings of the library are produced routinely. The angular distributions are normalized to unity in the billary form of the library co that renormalization is not necessary if the cross section is changed. The plot of the angular distribution for a given energy is normalized so that $2 \pi$ times the integral over the cosine of the scattering angle is the cross section for the reaction at that energy. This method of plotting has been found to be the most convenient one for checking purposes. Neither the total 


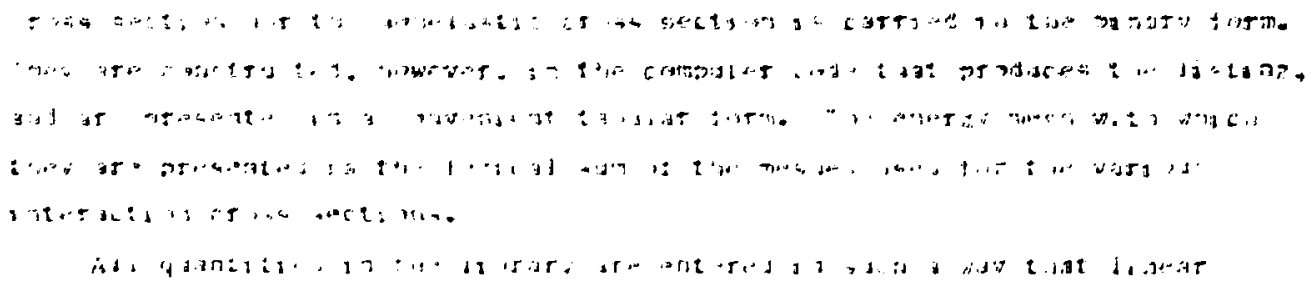

liorarios are ilentified by a version mmber, and successive editions or a version liave consecutive editron numbers.

\section{CONUFNTIONS MIND METHODS OF FVAT'ATION}

The basic principle adherod to in evaluations done at LI.NL is to present the maximun information content in as simple a furm $=s$ possuble. All 
interpoluble qunticies for neurron-induced reactions are presented so that limear interpolation becween successive entries yields values that are consistent with stated experimental errors, where experiments exist, or that edhere to an assumed lav, such as $1 / v$ energy dependence, within a suall fraction (typically $1 \%$ ). In the case of an assumed energy-dependence law for cross sections, this is accomplished by creating a large number of fenergy, cross section) pairs by compiter and subsequently tninning the points to a specified accuracy, using the subroutine THINER. ${ }^{1}$

Although a linear interpolation requires more entries to describe some data than would a $\log -\log$ or semi log interpolation, there are two arvantages to using a linear iaterpolation: ( $(1)$ It eliminates a source of clerical error in defining the data in the library. (2) More importantly, the code ${ }^{2}$ that uses the evaluatej liorary for input must perform integrals of tne products of functions. If the functions are represented linearly, many of the necessary integrations can be done analytically by using the cheorem in Ref. 3 racher than an approximating method.

All angular distributions are differencial probabilities normalized to an integral of unity over the cosine of the scattering angle. All energy distributions of secondary particles are presenced as normalized Legendre polynomial representations $\pi^{\ell}\left(E+E^{\prime}\right)$. For most multibody reactions, only the $\pi^{0}\left(E+E^{\prime}\right)$ term is given.

Angular distributions are entered into the library in an energy mesh fine enough for a linear interpolation in energy at each cosine value. The linear interpolation will construct an acceptable angular distribution at an intermediate energy. Since two successive energy entries may require different cosine meshes, each distribution can be expanded tu a cummon cusine mesh, the logical sum of the meshes used for the two distributions. The interpolation is carried out on energy at each resultant cosine mesh point to obtain the angular distribution at the intermediate energy. The resultant distribution is then thinned, using the subroutine THINER. ' The integrals of the input angular distributions are normalized to unity, so the resulting interpolated angular distribution will be properly normalized before thinning. After thinning, its integral is renornalized to unity.

Energy distributions are normalized so that the ntegral over the secondary energy of the zero-order, energy-angle Legendre cuefficients, $\pi^{0}\left(E \rightarrow E^{\prime}\right)$, is unity. Interpolation in incident energy is accomplished 


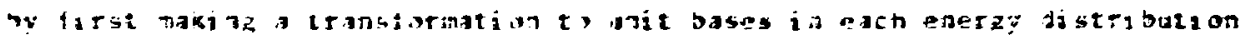

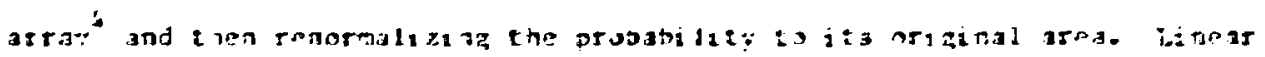

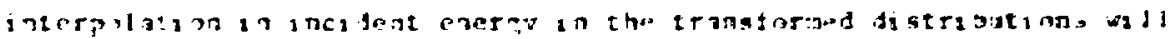

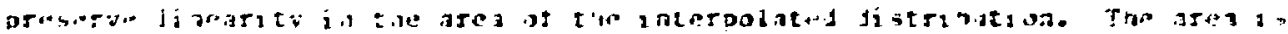

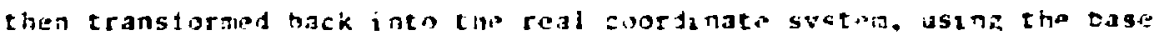

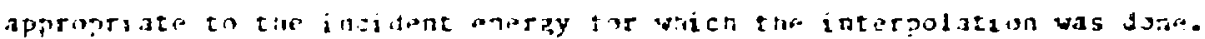

The qusting ot evaluatat dat sets is carried out routine: by calcalating the approstiats ousameters ot iate:ral neat on experionts and Crobring the calculations with fxperimental resules. The calculations are:

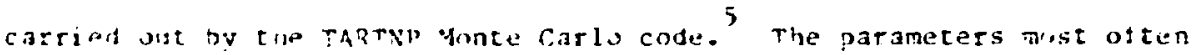

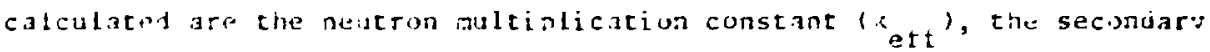
aeutron energv leakas s spectra trom critical assemblies, and the neutron or pnoton spectra trum pulsed sp reres. J kecause of the possioility or =ven likelihood of conpensating errors, sucin calculations cannot ensure tie validity ot the nuctear data even it the calculations arree vith tne experinents. They can, however, indicate the invalidity of tre lata if thé" do not asroe wita $t$ te experiments. Oa the other nand, it calculations for many disparate integrai experiments all show reasonable ajreement with the ineasirements, one can teel thac the evaluations are adequate for neatron transport calculations. This procedure does not provide a means tor assessing the validity ot the same data sots for activation analysis or otner I 7 intransport purposes.

ihe methods used to prodice an evaluated data set tor neutron Jata are described in Vol. IjA ot this series. Fvaluations tor specific materials are described i.i Vol. İD, Rev. 1 .

\section{ENCODIXG SYSTEY AND INPUT FORMAT FOR THE}

LINL EVALIJATFD NITCLEAR DATA IJTBRARY

The current encoding system for the IJVT, Fvaluated Nuclear Data Library is based, in large part, on experience wi th the I.LVT, experimental neutron cross-section liorary. 7 Table 1 shows the information tal is general to the entire library. Inits are b (barns), Mev, sr (steradians), and sh (shake; 1 shaine $=10^{-8} \mathrm{~s}$ ) except it noted otherwise.

The layout of the binary $f i$ le is explained in the tourth section of this report, but the following orief description of tne organization of the tile is 
presented here. The data for each nucleus are treated separately with

appropriate header inforation. The properties of a given nuclear

reaction--e.8., integraced cross sections, angular or energy-angulat

distributions, etc.--are filed together. Thus, che system is oriented to the

complete definition of a nuclear reaction, with the reactions appropriate to a particular target nucleus filed together. This is in contrast to other

systems in which all integrated cross sections for a nucleus are filed

togecher.

Both the incident particle, $y_{i}$, and the outgoing particle of interest, $y_{0}$, are designated according to tne dictionary in table 2. The appropriate property of the nuclear reaction is defined by the I number (Table 3). The nuclear reaction is identiiied by the $C$ number (Table 4 ). Any limitation or restriction placed upon the nuclear reaction is designated by an $S$ nurber (Table 5). Field definitiors are given in Table 6.

TABLE 1. Input information for the LLNL Evaluated Nuclear Data Library.

\begin{tabular}{|c|c|c|}
\hline $\begin{array}{l}\text { Incident and } \\
\text { emitted particles }\end{array}$ & $\begin{array}{c}\text { Energy range } \\
(\mathrm{MeV})\end{array}$ & $\begin{array}{l}\text { Interpolation } \\
\text { method }\end{array}$ \\
\hline Neutrons & $10^{-10}$ to 20 & Tinear-linear basis \\
\hline Photons & $10^{-3}$ to 100 & $\begin{array}{l}\text { Linear, on a } \log -\log \text { basis } \\
\text { (except for some transfer data) }\end{array}$ \\
\hline Charged particles & $10^{-10}$ to 20 & Linear-linear basis \\
\hline
\end{tabular}


TABLE 2. Parcicle designacor, y.a

\begin{tabular}{|c|c|}
\hline$y$ & Particle \\
\hline 0 & Not applicable ${ }^{b}$ or none \\
\hline $\mathbf{l}$ & $\mathrm{n}$ \\
\hline 2 & P \\
\hline 3 & d \\
\hline 4 & e \\
\hline 5 & $3_{\mathrm{He}}$ \\
\hline 6 & $\alpha$ \\
\hline 7 & $\gamma$ \\
\hline 8 & $B^{+}$ \\
\hline 9 & $B^{-}$ \\
\hline 10 & $\mathrm{EC}$ \\
\hline 11 & $\mathrm{n}$ as residual nucleus \\
\hline 12 & $\mathrm{p}$ as residual nucleus \\
\hline 13 & d as residual nucleus \\
\hline 14 & $t$ as residual nucleus \\
\hline 15 & ${ }^{3} \mathrm{He}$ as residual nucleus \\
\hline 16 & $\alpha$ as residual nucleus \\
\hline
\end{tabular}

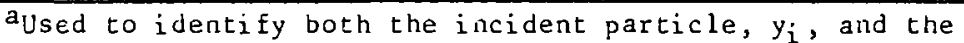
outgoing particie, $y_{0}$, to which any distribution data (e.g., energy, angle) pertain: $y_{i}=0-7$ only; $y_{0}=0-16$.

bIf no property (e.g., energy distribution) is given, the $y_{0}$ is zero or left blank in input. If $y_{i}$ is zero or blank, the data that follow are nuclear structure data.
} 
TABLE 3. Reaction property designator 1.a

\begin{tabular}{|c|c|c|}
\hline$I$ & Reaction property & Definition \\
\hline () & Integrated cross sections (b) & $\sigma(E)$ \\
\hline 1 & $\begin{array}{l}\text { Angular distributions, normall zed probabilities } \\
\text { (per unit cusine)! }\end{array}$ & $P(E, \mu)$ \\
\hline 4 & $\begin{array}{l}\text { Energy-angle di-iributions, normalized Legendre } \\
\text { coefficients. } \pi^{\prime}\left(E \rightarrow E^{\prime}\right)=p\left(E^{\prime} \rightarrow E^{\prime}\right) \text {, } \\
\text { the usual normalized energy probabilicy (per Ye:) }\end{array}$ & $\pi^{2}\left(E+E^{\prime}\right)$ \\
\hline 7 & $\begin{array}{l}\text { Average number of neutrons per fission } \\
\text { (prompt or delayed) }\end{array}$ & $v(E)$ \\
\hline$\alpha$ & Histogram form of energy distrioution ( $M \in V$ ) & $\int ?\left(E, E^{\prime}\right) d E^{\prime}$ \\
\hline it & Puoton or particle multiplicity & $\because(E)$ \\
\hline 10 & Average energy of a sezuairy particle (Yev) & $\bar{E}\left(y_{0}, \overline{)}\right)$ \\
\hline i 1 & Average energy of a residual nucleus (hev) & $\bar{E}^{\prime}(\mathrm{R}, \mathrm{E})$ \\
\hline iij & Axwell average reaction rates $(b-c m / s n)$ & $\overline{\sigma v}(k T)$ \\
\hline $6 !$ & In-Eligit (Doppler-broadened) cross sections (b) & $\sigma(k T, E)$ \\
\hline 3.4 & Yaxwell-averaged entergy distribucions (per Mev) & $P\left(k T, E^{\prime}\right)$ \\
\hline 40 & $\begin{array}{l}\text { Maxwell-overaged total average energy } \\
\text { ur particle (iev) }\end{array}$ & $E^{\prime}\left(y_{0}, k T\right)$ \\
\hline 91 & iarawell-averaged average energy ot residual & $\overline{\mathrm{E}}^{\prime}(\mathrm{R}, \mathrm{kT})$ \\
\hline$y 2$ & $\begin{array}{l}\text { Maxwell-averabei cutal average enersy of reacting } \\
\text { particles (vev) }\end{array}$ & $\overrightarrow{\mathrm{F}}(y \mathrm{i}, \mathrm{kT})$ \\
\hline
\end{tabular}

awe illustrate the use of these designatione by construating a reaction code fur lae energy distribution of protons from the 58 ivi (n, n ${ }^{1}$ ) ${ }^{57}$ Co reactiun:

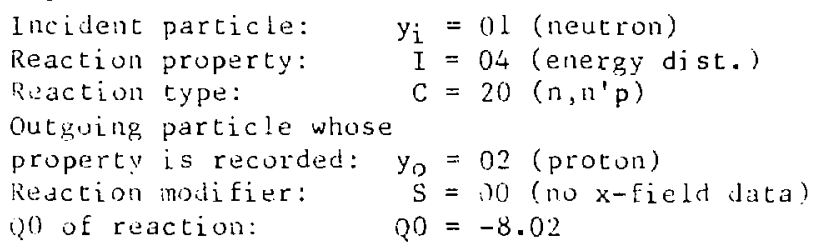

Tuis givos for the reaction code

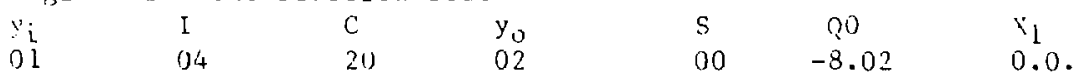

Dinguliar daca are expressed in the cencer-of-mass ( $c m$ ) system for all two-body breakups. Multibody breakups are, of cc.rse, in the Laboratory system. 


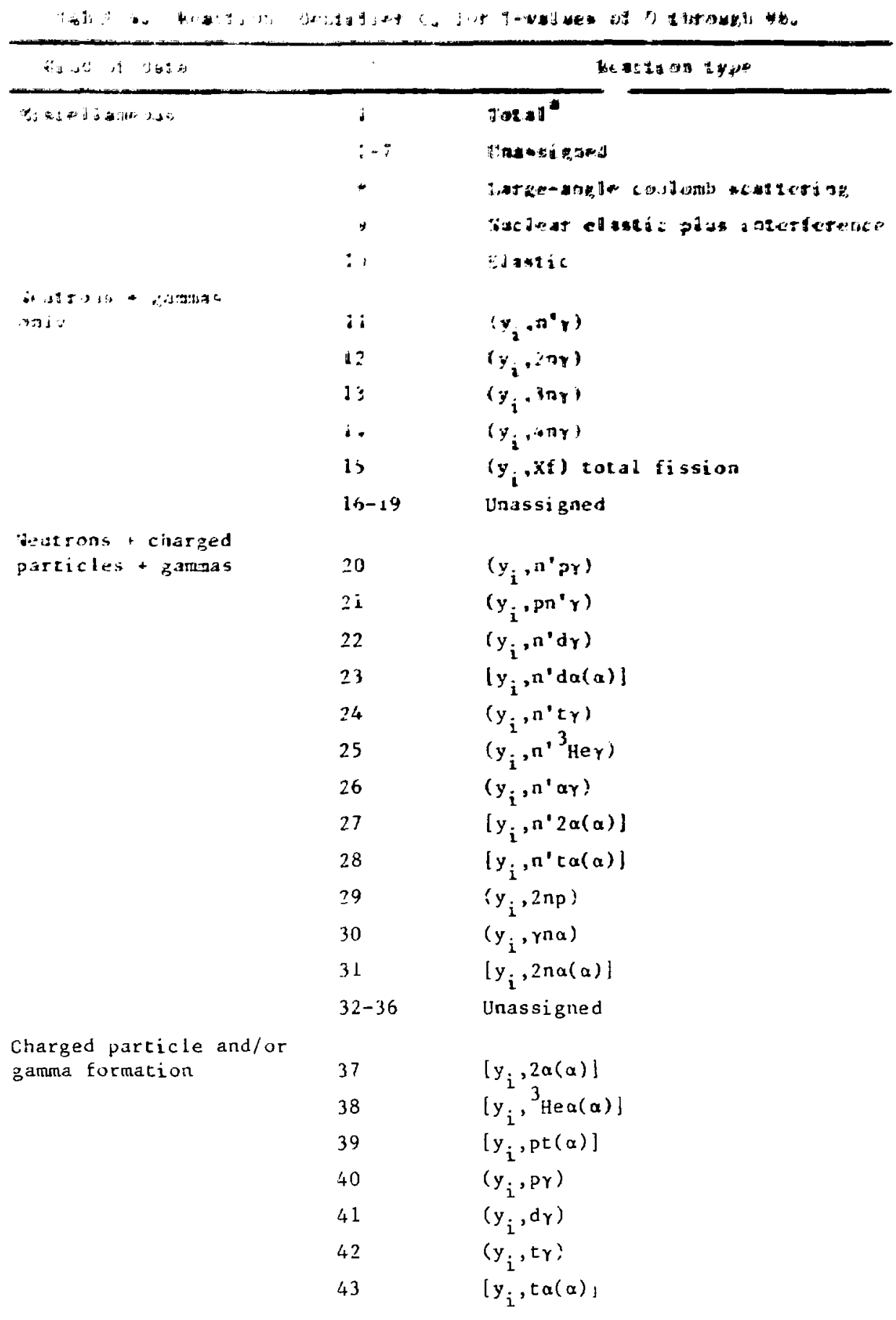


7AtZE 6. Roati naed.

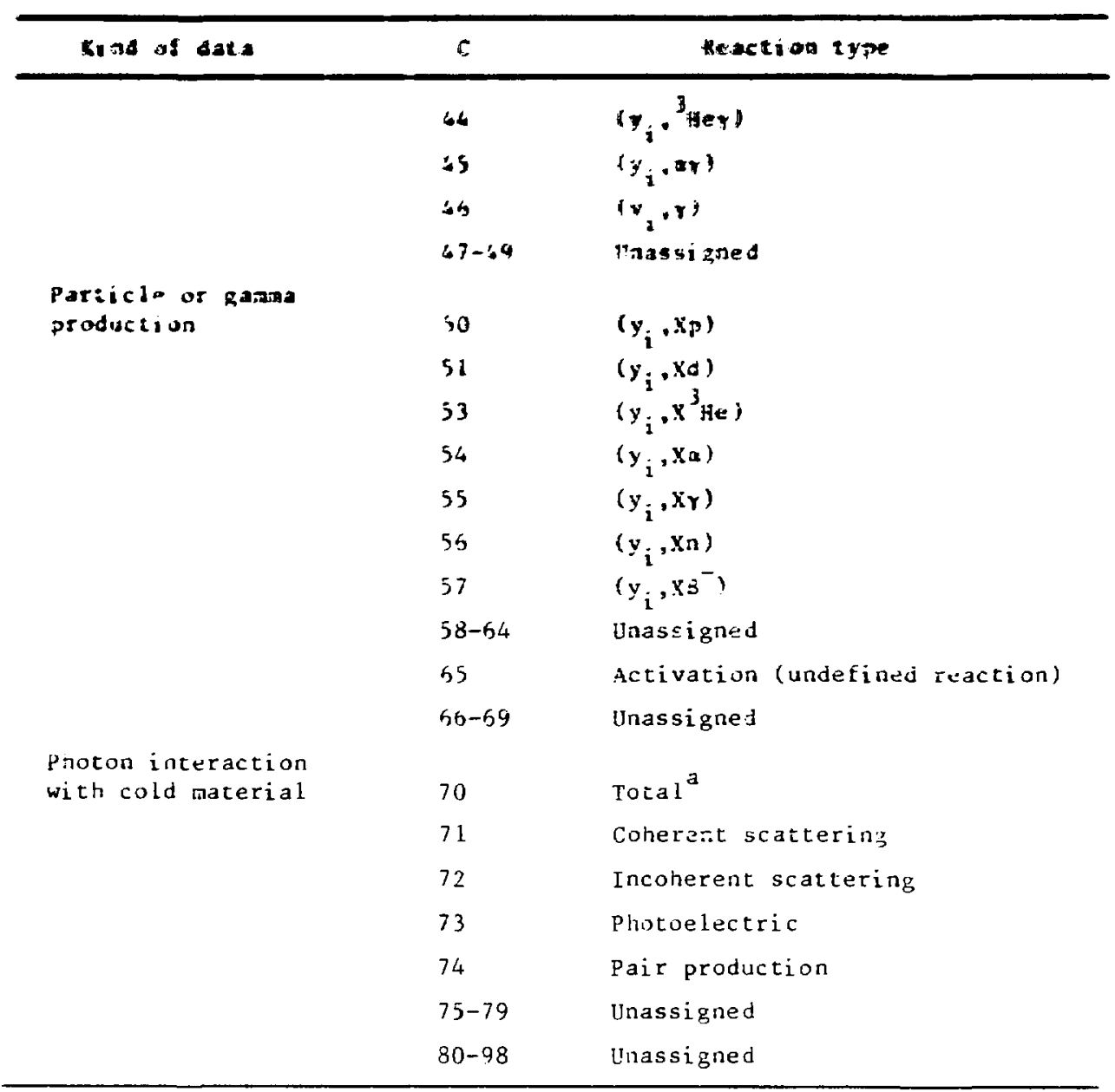

\footnotetext{
a Not stored in the system but obtained for output display and transmission format by combining other data.
} 
TAste 5. Heacion modiduet. 5.

\begin{tabular}{|c|c|c|}
\hline $\mathbf{s}$ & Reartion paramecer & x yela dotinitan \\
\hline $90 \mathrm{st}$ & & \\
\hline $\sin \alpha$ & is $x-f i e d d$ dat & $\cdots$ \\
\hline $01^{a}$ & Level mxcitation & $\omega_{i}($ Hev $)$ \\
\hline 112 & $\begin{array}{l}\text { 2nd particle from time } \\
\text { sequential reaction }\end{array}$ & $w_{i}\left(Y_{e} V^{\prime}\right)$ \\
\hline 03 & Gama-ray production & $E_{i}($ HeV $)$ \\
\hline $05^{\circ}$ & $A=t i v a t i o n$ & $\begin{array}{l}(\mathrm{ZA})_{2}, \mathrm{~N}_{2}(\mathrm{YeV}) \\
\operatorname{nalf}-1 \mathrm{ife} \text { (s) }\end{array}$ \\
\hline 07 & Delayed group half-lives & ${ }^{t} 1 / 2^{(s)}$ \\
\hline 08 & Completely correlated $n, 2 n$ & $\mathfrak{W}_{1}(\mathrm{MeV})$ \\
\hline 10 & Wide level exci+tion & $W_{1}(\mathrm{MeV}), \Gamma_{1}(\mathrm{MeV})$ \\
\hline 11 & $\begin{array}{l}\text { Second particle from wide } \\
\text { level time-sequential reaction }\end{array}$ & $W_{2}(M e V), \Gamma_{2}(\mathrm{MeV})$ \\
\hline $13^{c}$ & $\begin{array}{l}\text { Photon production from } \\
\text { known level excitations }\end{array}$ & $\omega_{1}(\mathrm{MeV}), \mathrm{E}_{\gamma}(\mathrm{MeV})$ \\
\hline
\end{tabular}

\footnotetext{
${ }^{a} X_{1}$ corresponds to the inicial nucleus, $X_{2}$ to the second nucleus in $a$ sequence of de-excications, etc.

$\mathrm{b}(\mathrm{ZA})_{2}=1000 * \mathrm{Z}_{2}+\mathrm{A}_{2}$ DE product nicleus.

$c_{W_{1}}$ corresponds to the levei excitation energy, and $E_{y_{1}}$ is the energy of the photon.
} 


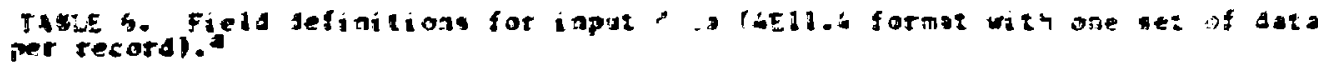

Dera surec ia field

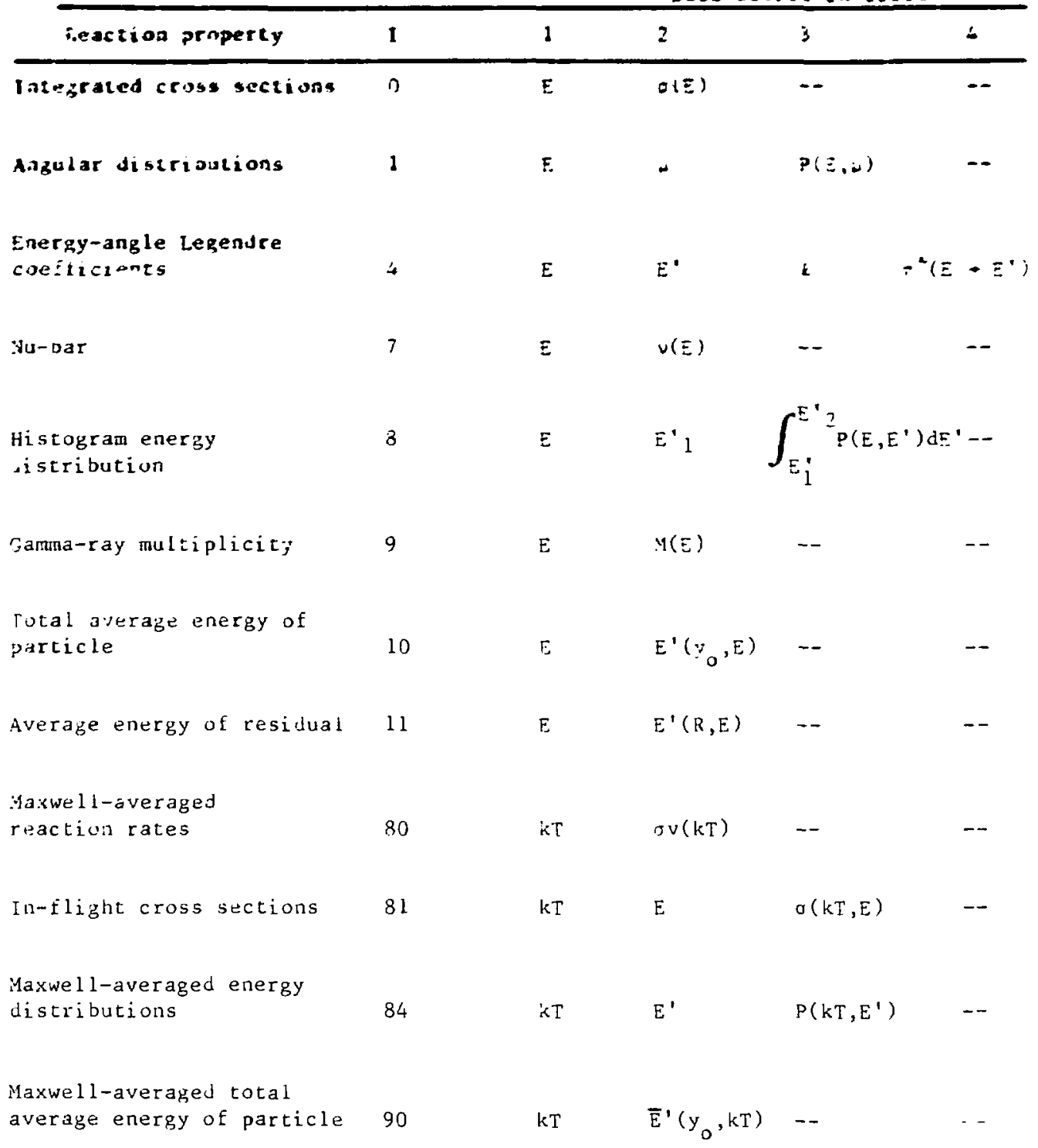




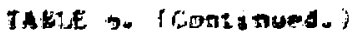

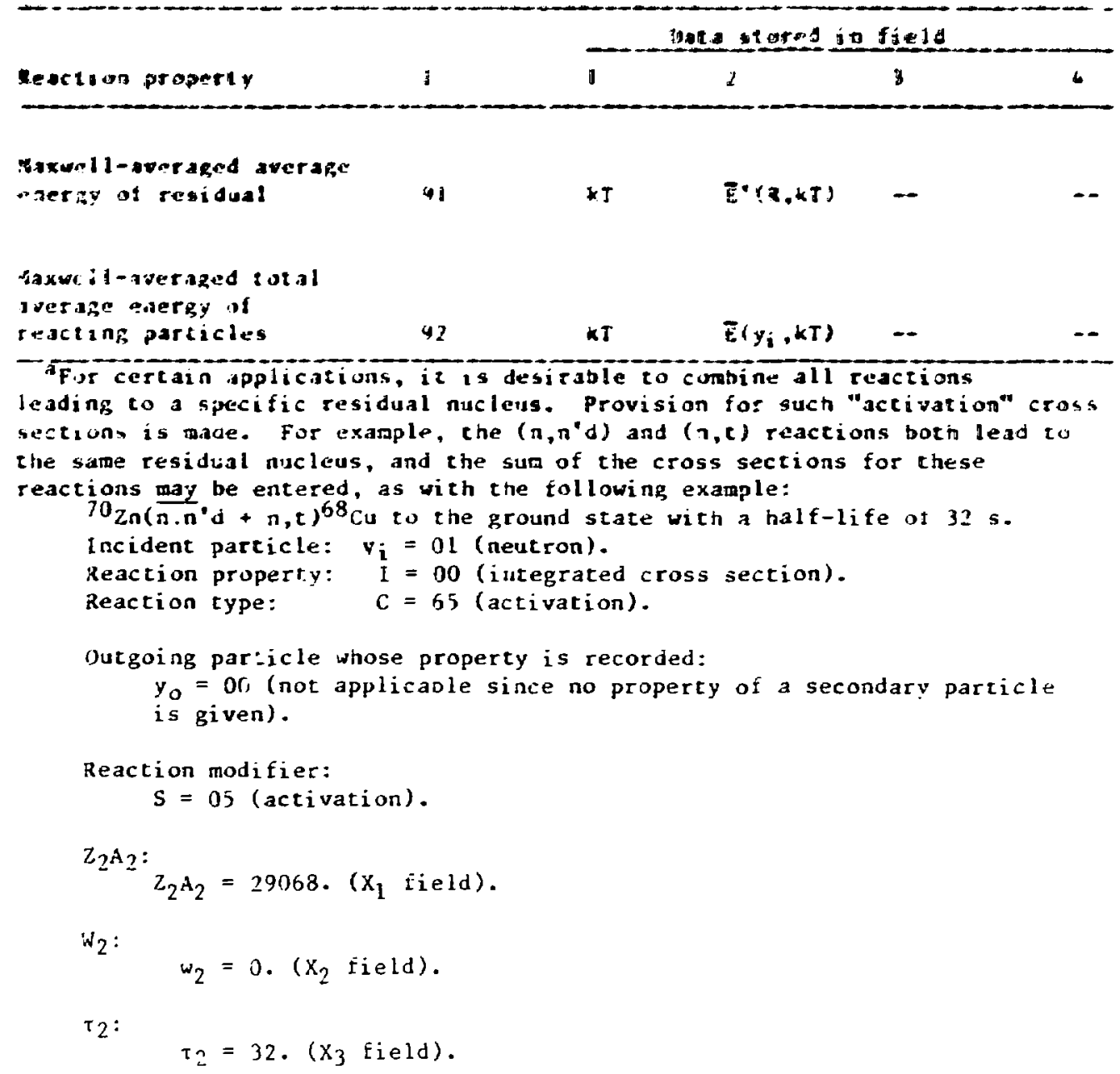

For the reaction code this gives

$\begin{array}{lllllllll}y_{i} & I & \mathrm{C} & y_{0} & \mathrm{~s} & \mathrm{Q} 0 & x_{1} & x_{2} & x_{3} \\ \text { ol } & 00 & 65 & 00 & 05 & & 29068 . & 0 . & 32 .\end{array}$




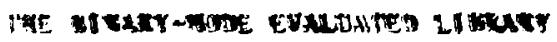

Thi section present the layout of the bisary libery .ile and

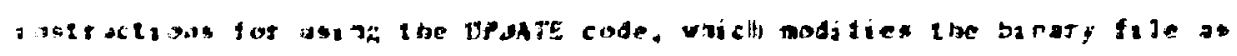

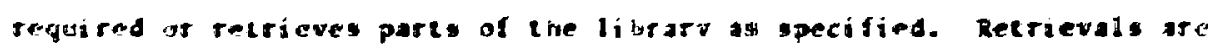

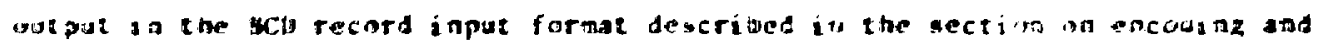
lapa: cormat. UPDATE is witen in IRLTRAs and, as described bete, can de run

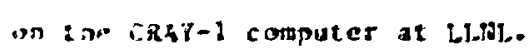

The code reaus either the delete and inswri records is the retricial request records. A retrieual cannot be made during a rus shat deletes or inserts dala. The format of the input records is the same tur delezion and retrieval except for a flag designating the typ of operation.

for either deletion or rerieval two sets of three records each are required to define the range of daca to be deletted or retrieved. Data may be deletei or retrieved for any nume: of ranges, but each range rast be defined py the two sets of three reccrds. The first record of each set (sarget record) specities the limits of the range of isotopes or eletients (using ine $1000 \% Z$ + A convention described in the third section ui this report), the incident and sécondary particles of interest, and the type of operation to de performed (i.e., retrieval or deletion). The second record of each set (reaction record) specifies the limits of tne range of reaction descriptors, and the third record of each set (data record) gives the limits of the energy range of the independent variables for which the deletion or retrieval is to be performed. The specification of the fields of these cards can be fuund in rable 7 , for tne first two car's of act set. Foz liw chird card, the rormats and specifications are described in Table 5 .

There are several special types of deletions:

1. To delete an entire isotope or elemient (ZA), set $c_{\min }=1, c_{\max }=99$. All other fields of the reaction record and data record nay be left blank.

2. To delete a particular reaction (C) or a range of reactions, set:

$$
\begin{aligned}
& C_{\text {min }}=\operatorname{minimum} C \text { to be deleted, } \\
& C_{\text {max }}=\text { maximum } C \text { to be deleted, } \\
& I_{\min }=0, \\
& I_{\max }=99 .
\end{aligned}
$$

All other fields must be set to the minimum-maximum range desired. 


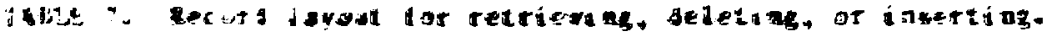

\begin{tabular}{|c|c|c|c|c|}
\hline & $\cos 1 \sin 3 \%$ & Format & vme & theseration \\
\hline \multirow[t]{8}{*}{$\operatorname{cocos} 21$} & $1-6$ & 3*, & $Z_{A}$ & $16 \cos _{0} 0 * z+4$ \\
\hline & $5-1$ & 12 & $y_{i}$ & isciden: particle descriptor \\
\hline & $11-1 ?$ & $I:$ & ." & Outzming purticle descriptor \\
\hline & $1.4-2 \%$ & 1.11 .6 & & Atomic mass for this Zh (amu) \\
\hline & $29,-31$ & It) & iat." & Currens date (YYWWD) \\
\hline & $33-3 i$ & 12 & Flai: & $\begin{array}{l}\text { Desamantes the type of uperation: } \\
!=\text { delete, } 2 \text { insert. } 3 x \\
\text { retrieve. }\end{array}$ \\
\hline & $35-15$ & E.1:.4 & & Level energy of the carget (yev) \\
\hline & $48-58$ & E 11.4 & & Half-life of the target ${ }^{0}(s)$ \\
\hline \multirow[t]{7}{*}{ Record 2} & $1-2$ & I 2 & $c^{a}$ & Reaction number \\
\hline & $3-j$ & 13 & $I^{a}$ & Reaction property designator \\
\hline & $6-8$ & I 3 & $s^{3}$ & Reaction modifier flag \\
\hline & $10-20$ & E11.4 & $\mathrm{qo}^{\mathrm{a}}$ & $\begin{array}{l}\text { Mass difference } Q \text { for the } \\
\text { reaction }\end{array}$ \\
\hline & $2 \div-32$ & E 11.4 & $\mathrm{x}_{1}^{\mathrm{a}}$ & Value depents upon the value of 5 . \\
\hline & $34-44$ & E 11.4 & $x_{2}{ }^{a}$ & Value depends upon the value of $\mathrm{S}$. \\
\hline & $45-56$ & E 11.4 & $x_{3}{ }^{a}$ & Value depends upon the value of $S$. \\
\hline
\end{tabular}

\footnotetext{
${ }^{a} A$ more complete definition of these fields can be found in Tables 2-5.

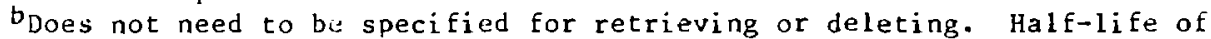
the target must be specified only when the material is entered for the first tine.

3. To delete all of a particular reaction property designator (I), leave both data records blank. All other fields must be set to the minimum-maximum range desired.

If the limits specified by the delete request cannot be satisfied, a comment is printed and the code continues. The data sets representing deletions and insertions may be in any order in the input file. The code sorts the sets, performs the deleting operations, and then inserts new data, one target at a time.

If data are to be inserted into the library, the first two records (the target and reaction records) must be as described in Table 7 . These records 


\begin{abstract}
determine the point in the library at wich ineertions are to be made. Ttr third and following recorbs are dats recos fs containing ab ata in be inserted: ther ate pqecified with respect to the format axt coarcht deactibed in Table 4 . Follwing the last rocort of earb data set to be anersed is a record with the numer 1 in colvm 72 . There is no 1 init $t$, the number of

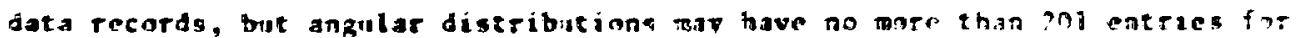
oach incident energy. Whenever appropriate, data are nerged with erating data, but if equal points are encountered in the merge, they are printed out with the original data left in the library. The code then proceeds. If a match cannot be made between the specifications stated on the first two records of a set to be inserced and those found on the evaliatad ibraz', a nes isotope (ZI), a new reaction (C), a new reaction modifier (S), any oz the $x_{i}$ fields, or a new reaction sroperty designator (I) is created to fulfill the required specifications. Insert requests are read by the code until it senses an end of file, which signals the code to begin processing the requests.

There is ro limit to the number of delete and insert requests tiar can be
\end{abstract} present.

A!thougls the significance of kaking an entry for the outgoing particle is discussed in the third section of this report, it is well to re-emphasize that ai entry is made for that quantity if, and only if, the data being described pertain to the outgoing particle. For example, the cross section for an $\left(n, n^{\prime} p\right)$ reaction would be entered without specifying al, outgoing particle, while an energy distribution of the resulting neutrons would require an entry of 1 for the $y_{0}$ (outgoing particle) and an energy distribution for the resulting protons would require a 2 for the $y_{0}$. With tisis feature it is possible to specify completely all aspects of reactions having more than one type of emergent particle.

There are several different forms of printout from the code that tell the user what has been done. The order of the output is as follows:

1. The evaluated library identification word from the input library is decoded and printed with appropriate labels describing the meaning of each quantity. This is followed by the date for this library.

2. The delete and insert requests or the retrieve requests are printed as they were read from the input cards.

3. A printout is made showing the computer tume used to process this update. 


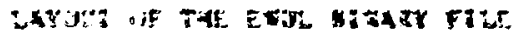

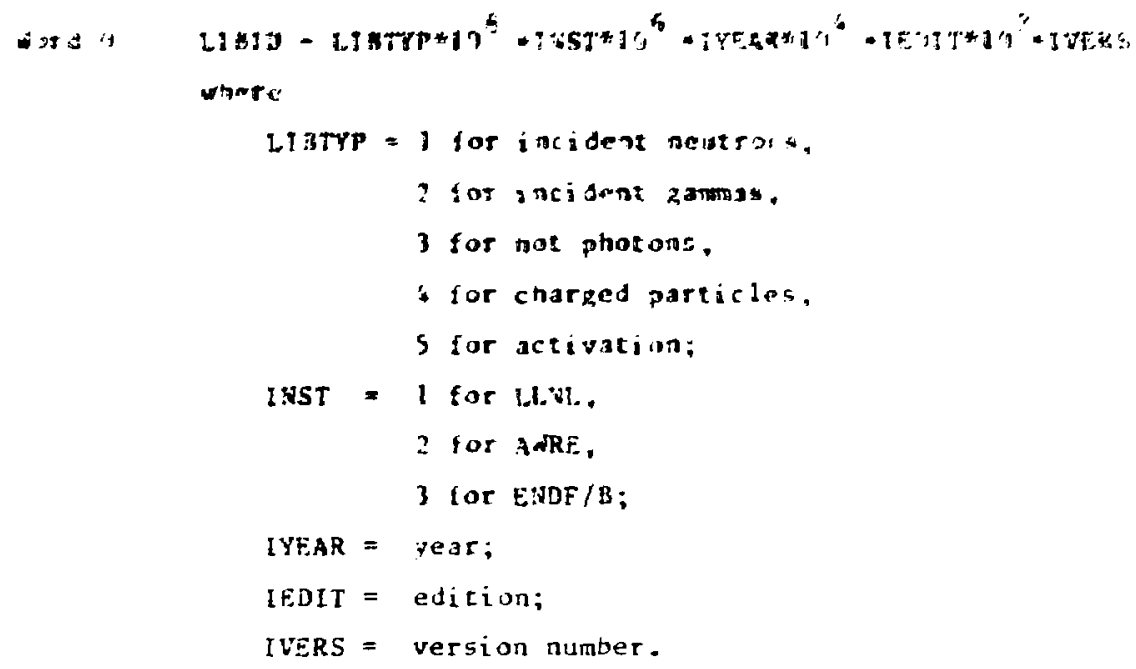




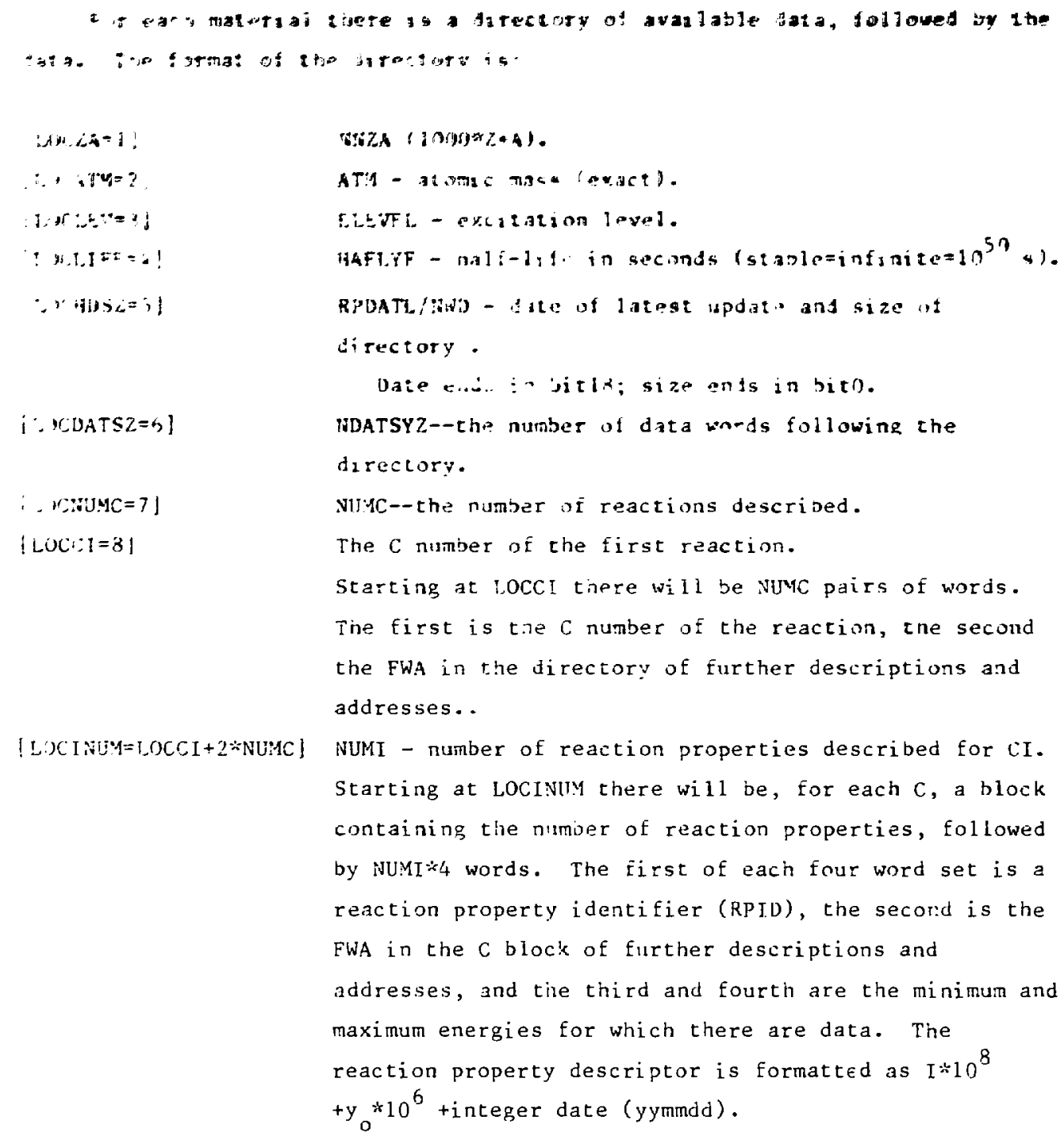

The first ( block within the material directory starts at LOCINUM + NUMC + NUMI *4. The storage hierarchy for each material is $y_{i}, C, S, Q 0, X 1, X 2$, $\mathrm{X} 3, \mathrm{y}_{\mathrm{o}}, \mathrm{I}$. 


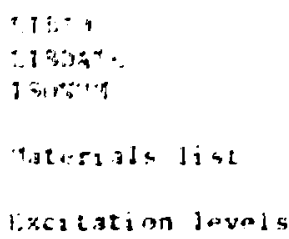




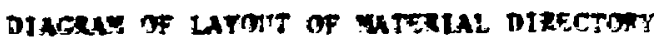

\begin{tabular}{|c|c|}
\hline Locza & $\operatorname{Mr} 2 \mathrm{~A}$ \\
\hline Lacety & ATM \\
\hline LOCLEV & ELEVEL \\
\hline LOCLIFE & HAFLYF \\
\hline LOCADSZ & RPDATE/IND \\
\hline $\begin{array}{l}\text { Locotsz } \\
\text { EOCNuHC }\end{array}$ & $\begin{array}{l}\text { TDATSYZ } \\
\text { TUWC }\end{array}$ \\
\hline \multirow[t]{6}{*}{ Locer } & Cl \\
\hline & FWA C1 \\
\hline & $c 2$ \\
\hline & FAA C2 \\
\hline & Clast \\
\hline & Fld Clast \\
\hline \multirow[t]{25}{*}{ LOC INUM } & NIJMI Cl \\
\hline & RPID CIII \\
\hline & FWA CII 1 \\
\hline & EMI :T \\
\hline & EMAX \\
\hline & RPIU CII2 \\
\hline & FWA CII 2 \\
\hline & EMIN \\
\hline & EMAX \\
\hline & RPID ClIlast \\
\hline & FWA ClIlast \\
\hline & EMIN \\
\hline & EMAX \\
\hline & NUMI C2 \\
\hline & RPID C2I 1 \\
\hline & FWA C2I I \\
\hline & EMIN \\
\hline & EMAX \\
\hline & RPID C2I 2 \\
\hline & FWA $\mathrm{C} 2 \mathrm{I} 2$ \\
\hline & EMIN \\
\hline & EMAX \\
\hline & RPID ClIlast \\
\hline & $\begin{array}{l}\text { FWA C2Ilast } \\
\text { EMIN }\end{array}$ \\
\hline & EMAX \\
\hline
\end{tabular}




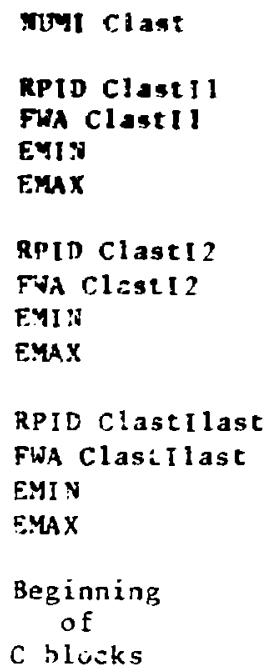


DIAGRAS OF EATOUT OF C BLOCKS

\author{
Find in \\ data section \\ of data for \\ this $C$ \\ LWA in \\ Jata section \\ of data for \\ this $C$ \\ $y_{i}$ \\ Cdate \\ $s$ \\ $Q^{4}$ \\ $\because n 1$ \\ $x 2$ \\ X3 \\ Unused \\ Unused \\ I Block \\ For I 1 \\ I Block \\ for $[2$ \\ I Block \\ for Ilast
}




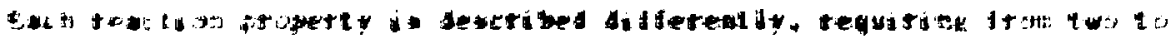

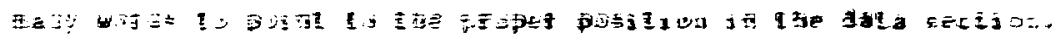

I = ketergat frose bectioa*

Fint ior $i=0$

Lith Aar: $=3$

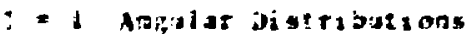

Fin for $i=1$

is

Yaxi num nutabiz of $[\mu, p(x)]$ paiss

wumber al inciden: energies

Fwh of data for lst incident enersy

Fol of data for 2nd incident energy

-

$\cdot$

Fis of data for last incident energy

$I=4$ Energy-angle Legendre coefficients

Fis For $\mathrm{I}=4$ data

Lid for $I=\dot{\text { data }}$

Maximum order of $\ell$

Yaxi num number of incident energies;

Maximum number of target energy-probability pairs per incident energy

FWA for $\ell=0$ data

FWA of data for first incident energy

-

-

F'NA of data for last incident energy

FWA for $\ell=1$ data

.

•

FWA for maximum order \& data

number of incident energies for this $\ell$

FWA of data for first incident energy

.

.

FWA of Jata for last incident energy

$I=7$ Average neutrons per fission (prompt or delayed)

FWA for $I=7$

LWA for $I=7$ 


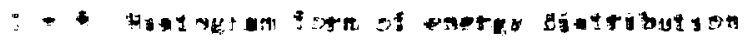

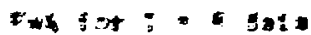

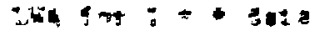

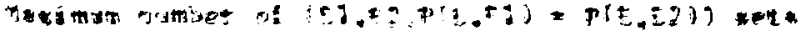

Wutber of lacidand mereven

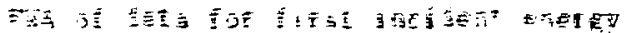

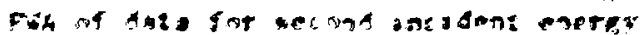

-

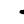

i. if As:a for 3ast incigent enerdy

$T=$ Matiolocitaces

Fif for $:=0$

linf fir $i=0$

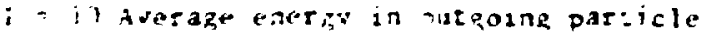

$\because i f \mathrm{f} J \mathrm{~J}=1 \mathrm{n}$

int for $I=10$

I = 11 fuerage energy of residual nucleus

Fis for $I=11$

init For $I=11$

$j=3 n$ laxwellian averaze roaction rates

FWA for $T=80$

LNA for $I=80$

$I=81$ in-flight reaction cross sections

FWA for $I=81$

LWA tor $I=81$

Maximum number of $\{E$, sigma(E)\} pairs

Number of incident temperatures

FWA of first incidenr. temperature

Fiva of second incident temperature

-

FWA of last incident temperature

$I=84$ Maxwell-averaged energy distribution from thermal equilibrium reactions

FWA for $I=84$

LWA for $\mathrm{I}=84$

Maximum number of $(E, P(E))$ pairs 


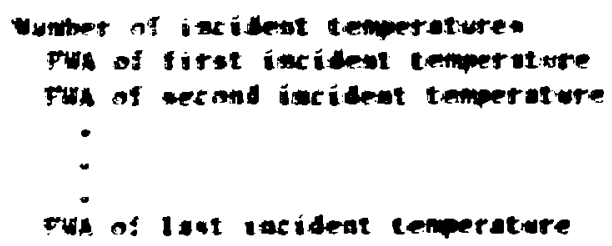

FWA for $t=91$

IjA for $I=91$

1. 92 Maxuell-averaged total average energy of reacting particles

FWA for $I=92$

LWA for $I=92$ 


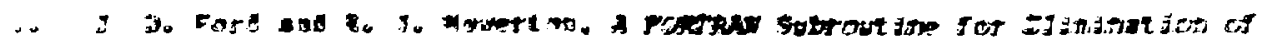

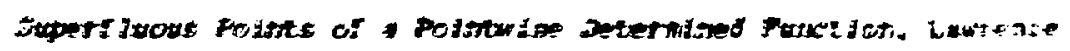

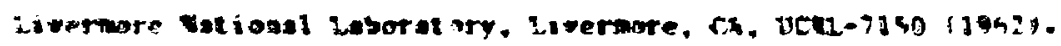

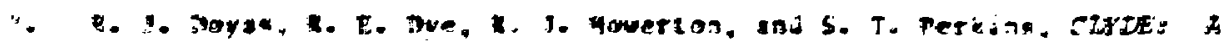

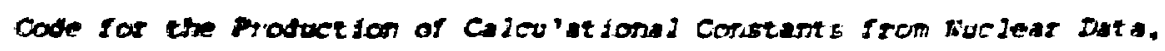

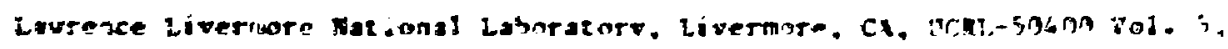
(and. 1975$)$.

3. K. E. yoa Holti and R. J. Moucston. Hazbematies of Ccrqutatson 17.619 (194):.

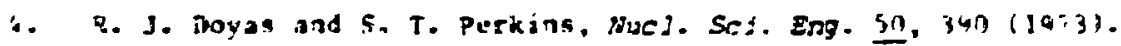

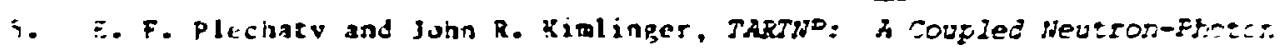
Monte Car 20 Transport Code, Lawrence Livermure National Laboratcry. Livermore, CA, JCRI,-50400, vol. 14 (1976).

6. R. J. Howe:ton, Data Testing Results for the LLL Evaluated : 20 lear Lata Library (ENDL-78), Lawrence Livermort Vational Laboratory, Livermore, CA, UCRL-50400, vol. is, Part E (1979).

7. D. E. Cullen, K. L. Hill, R. J. Howerton, and S. T. Perkins, ECSII: A System for Storage, Retrieval, and Display of Experimental Neutron Data, Lawrence Livermore National Laboratory, Livermore, CA, UCRL-50400, Vol. 1, Kev. 3 (1975). 


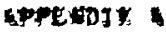

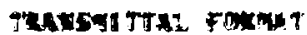

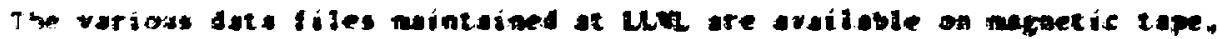

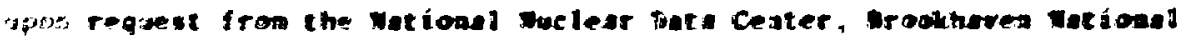

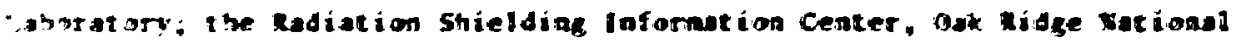
wabutator: and the Nuclear Data Section, Itaternational Atomic enerey Abeacy,

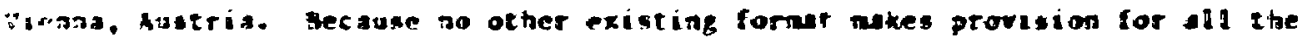
irnpertich that arc part of the Llid data files, a transmitial format has been founloped that is simple and closely relaced to the anput format for the updating code described in Tables 5 and 7 . The record layout fir the first two recorls of each set of data is given in Table $\lambda-1$. These first two records are called the header records. The records that follow the header records are appropriately called the data records, and the layout used for the data records is a function of the reaction property ("I-value") described in the second of the two header records. Only three types of layours, or

TABLE A-1. Fizld definitions for header recurds.

\begin{tabular}{|c|c|c|c|c|}
\hline & Columns & Format & Name & Description \\
\hline \multirow[t]{7}{*}{ Record 1} & $1-6$ & 16 & ZA & $1000 Z+A$ \\
\hline & $8-9$ & โ2 & $y_{i}^{3}$ & Incident particle descriptur. \\
\hline & $11-12$ & 12 & $y_{0}^{a}$ & Outgoing particle descriptor. \\
\hline & $14-24$ & E 11.4 & A & Atomic mass for this ZA (amu). \\
\hline & $25-31$ & I6 & DATE & Date last changed. \\
\hline & $35-46$ & E11.4 & & Level energy of the target (MeV). \\
\hline & $48-58$ & E11.4 & & Half-life of the target (s). \\
\hline \multirow[t]{7}{*}{ Record 2} & $1-2$ & I 2 & $c^{a}$ & Reaction number. \\
\hline & $3-5$ & 13 & $I^{a}$ & Reactiou property designator. \\
\hline & $6-8$ & I 3 & $s^{a}$ & Reaction modifier flag. \\
\hline & $10-20$ & E 11.4 & $\mathrm{QO}^{\mathrm{a}}$ & Mass difference $Q$ for the reaction. \\
\hline & $22-32$ & $\mathrm{EIL} .4$ & $x_{1}^{a}$ & Value depends upon the value of $s$. \\
\hline & $34-44$ & E 11.4 & $\mathrm{x}_{2}^{\mathrm{a}}$ & Value depends upon the value of $\mathrm{S}$. \\
\hline & $46-56$ & E 11.4 & $x_{3}^{a}$ & Value depends upon the value of $S$. \\
\hline
\end{tabular}

\footnotetext{
${ }_{A}$. nore complete definition of these fields can be found in Tables $2-5$.
} 


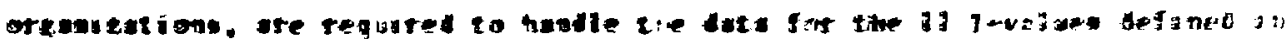
athe is.

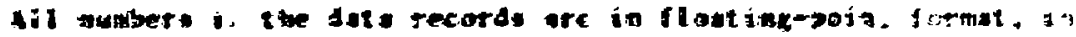

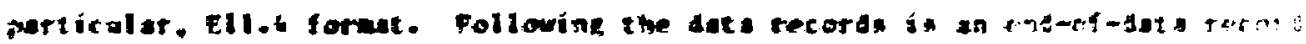

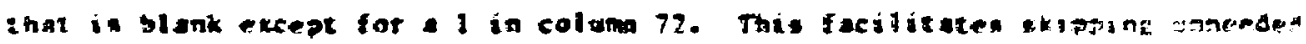

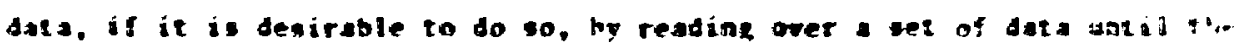

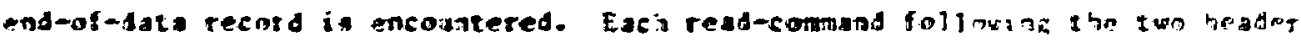
recesds way be donc vith a GE11.4, 5x, il sormit.

For $1=0,7,9,10,11,90,90,91$, and 92 , the first data recretgives: the number of pairs of independent/dependent variables to follow. Th. significance of the independent and dependert variables is given in tablet for rach I-value.

For $I=1,8, A 1$, and $B 4$, the first recard gives the number af values of the factorable paraneter (incident particle energy for $1=1.9 ; k$ for $1=$ 31, 84). The following data records are given in sets, with the number of sets equal to rt.e value given in the first-record described above. Each set has a first record that gives the value cf the parameter (E or $k T$ ), fo:lowed jy the number of pairs of indeperdent/dependent variables, silish are defined in Tablo 5 for each I-va!ue.

For $T=$ s there are two paraneters ( 2 and $F)$. The first data record

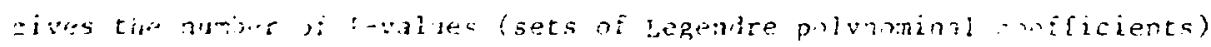
that follow. Fur aach set of coefficients, the first record rives the ordir iff \&, followel nv the number of incident-particle fnergies for which secondarv-enerzy/crefficient pairs are given. For eaci incident-particle eneray there is a record that gives the incident-particle energ: and the nilinber of pairs of secondazy-enirgy/coefficient pais that follow. Th. remaining data for that subset are the secondary-energy/coefficient values for that order of Legendre polynominals and that incident-particle energy.

Tables A-2, A-3, and A-4 give a schematic for the three [-valie-dependent laysuts. 


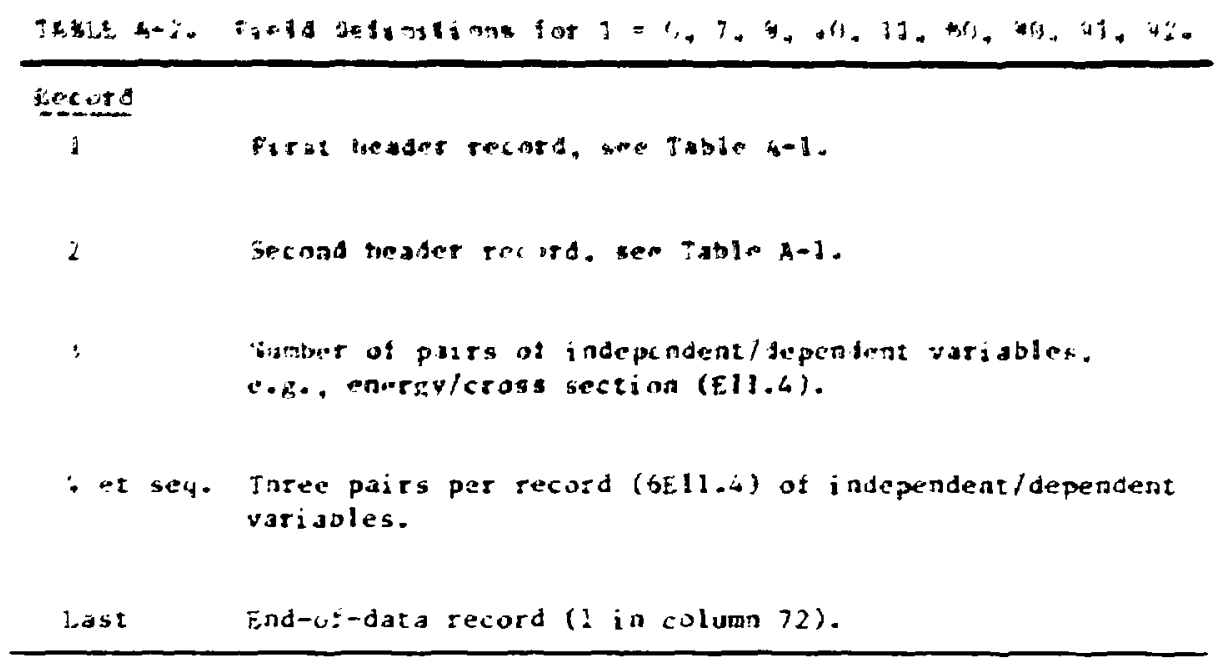

TABLE A-3. Field definitions for $I=1,8,81,84$.

\begin{tabular}{|c|c|}
\hline Record & \\
\hline 1 & First header record, see Table $A^{-1}$. \\
\hline 2 & Second header record, see Table $A-1$. \\
\hline 3 & $\begin{array}{l}\text { Number of values of the factorable parameter (NF) (Ell.4). } \\
\text { ( } E \text { for } I=1,8, \quad k T=\text { for } I=81,84) \text {. }\end{array}$ \\
\hline 37 & $\begin{array}{l}\text { Value of the factorable parameter, number of pairs of } \\
\text { i.aciepardent/dependent variables that follows (2El1.4). }\end{array}$ \\
\hline$j \in t \operatorname{seq} \cdot^{a}$ & $\begin{array}{l}\text { Three pairs per record }(6 F I 1.4) \text { of independent/dependent } \\
\text { variables }[e . g ., \text { for } I=1, ?, P(E, \mu)] .\end{array}$ \\
\hline Last & End-of-data record ( 1 in column 72$)$. \\
\hline
\end{tabular}

apepeaced NF times. 
TALt. A-í. Ficld definitions for $]=4$.

\begin{tabular}{|c|c|}
\hline Record & \\
\hline $\mathbf{I}$ & Farst beader record, see Tabie $\lambda-1$. \\
\hline$?$ & Second header record, see Table $A^{-1}$. \\
\hline 3 & Number of values of $\mathrm{R}(\mathrm{E} 1 \mathrm{l} .4)$, NL. \\
\hline$\therefore a$ & $\begin{array}{l}\text { Value of } R \text {, number of incident energies for tinis } R \\
(2 E 11.4) \text {, NE. }\end{array}$ \\
\hline $5^{b}$ & $\begin{array}{l}\text { Iacident energy; number of secondary energy coefficients to } \\
\text { foilow }(2 E 11.4) \text {. }\end{array}$ \\
\hline b et seg. is & $\begin{array}{l}\text { Three pairs per record ot secondary energies and coeificients } \\
(6 E i l .4) \text {. }\end{array}$ \\
\hline Last & End-of-data record ( 1 in column 72$)$. \\
\hline
\end{tabular}

aepeated NL Limes.

bepeated NE times. 


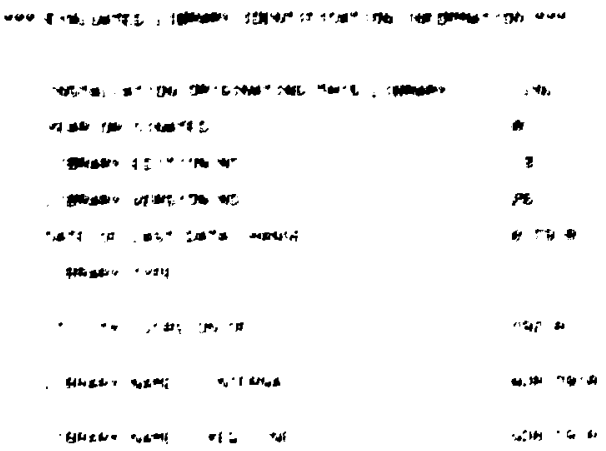

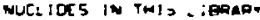

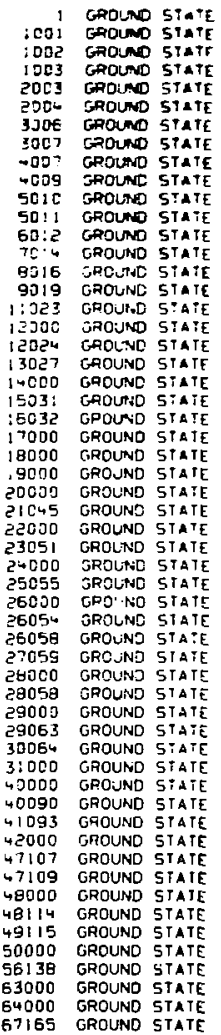




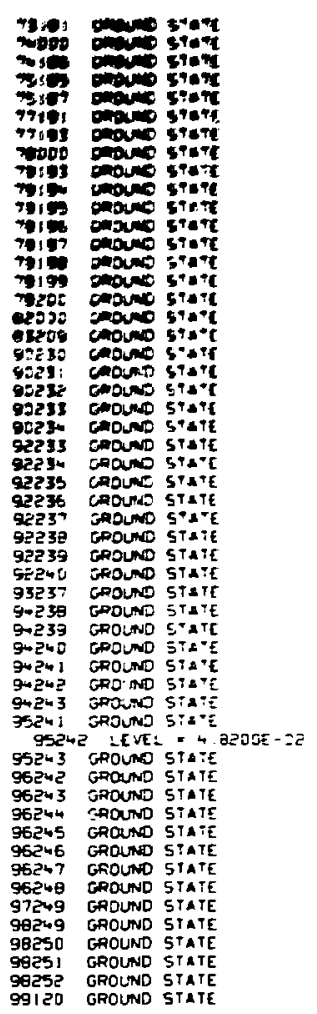

\begin{tabular}{ll} 
Y1.YO NO. & PARTICLE DESCRIPTION \\
\hline 00 & NOT APPLICABLE OR NONE \\
01 & NEUTRON \\
02 & PROTON \\
03 & DEUTERON \\
04 & TRITON \\
05 & AE-3 \\
06 & ALPHA \\
07 & GAMHA RAY \\
08 & BETA \\
09 & GETA- \\
10 & ELECTRON \\
11 & NEUTRON AS RECOIL NUCLEUS \\
12 & PROTON AS RECOIL NUCLEUS \\
13 & DEUTERON AS RECOIL NUCLEUS \\
14 & -RITON AS RECOIL NUCLEUS \\
15 & HE-3 AS RECOIL NUCLEUS \\
16 & ALPHA AS RECOIL NUCLEUS
\end{tabular}




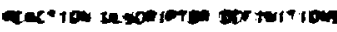

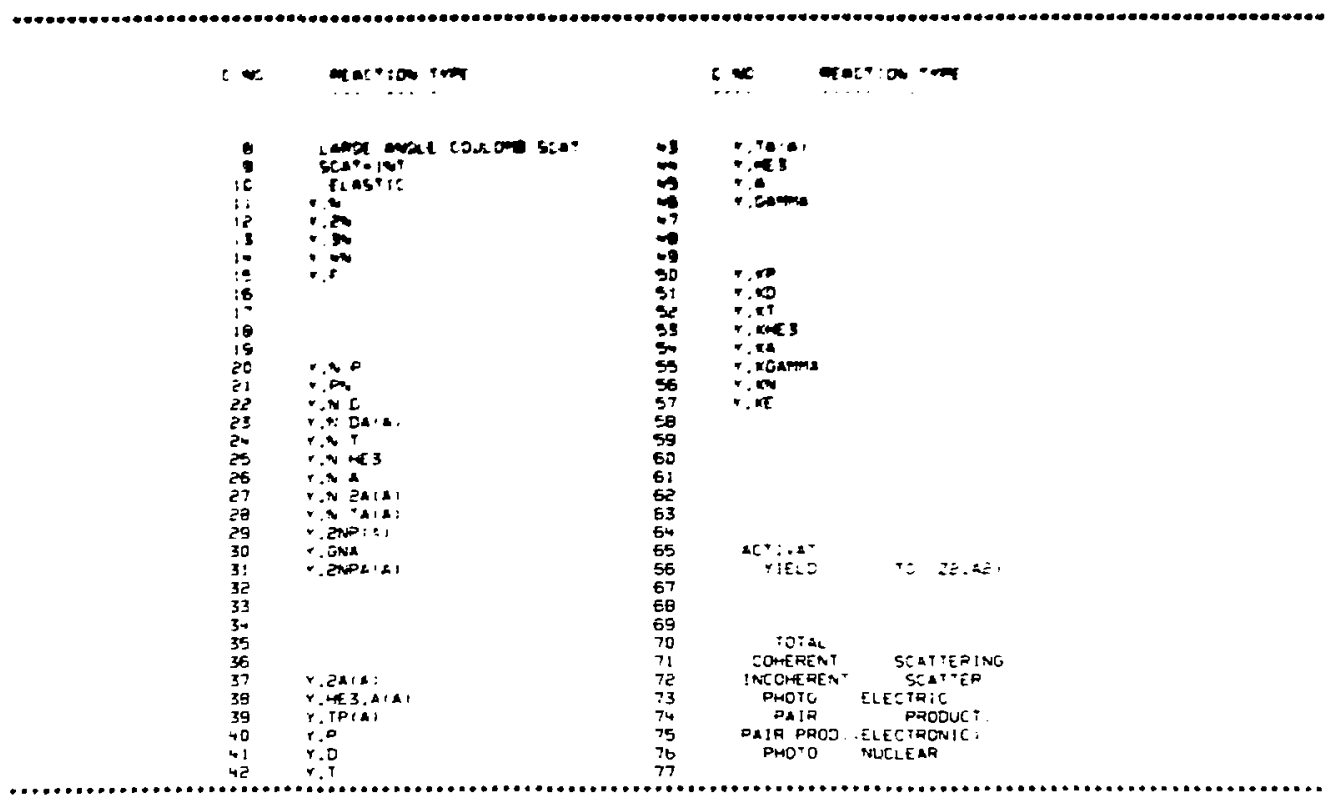

\begin{tabular}{|c|c|}
\hline$S$ NO. & SHITCH DESCRIPIION \\
\hline-2. & 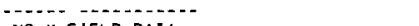 \\
\hline $\begin{array}{l}00 \\
01\end{array}$ & $\begin{array}{l}\text { NO X-FIELD DATA } \\
\text { LEVEL EXCIIATION }\end{array}$ \\
\hline 05 & $\begin{array}{l}X 1 \text { WIMEVI } \\
\text { PRE-EQUILIBRIUM AR.T UNRESOL VED DIRECT } \\
\text { INTERACT I ON PROCESSES }\end{array}$ \\
\hline 03 & $\begin{array}{l}\text { NO X-FIELD DATA } \\
\text { GAMMA-RAY PRDOUCTION }\end{array}$ \\
\hline & $X 1=$ E-GAM(MEV) \\
\hline $\mathrm{O}_{4}$ & $\begin{array}{l}\text { HATER I AL TEMPERATURE } \\
X I=K T(M E V)\end{array}$ \\
\hline 05 & $\begin{array}{l}\text { ACTIVATION } \\
\times 1=2 Z A 2, \times 2=\text { LEVEL, } \times 3=\text { HIIFE }\end{array}$ \\
\hline 06 & $\begin{array}{l}\text { DOPPLER BROADENING } \\
X_{1} \times K T, X E=N O, X 3 * T H\end{array}$ \\
\hline 97 & $\begin{array}{l}\text { DELAYEO GROUP HALF-LIVES } \\
X I=\text { SORTITAUI }\end{array}$ \\
\hline 08 & $\begin{array}{l}\text { COMPLETELY CORRELATED REACTION } \\
X I=\text { WIMEV }\end{array}$ \\
\hline $\begin{array}{l}09 \\
10\end{array}$ & $\begin{array}{l}\text { UNUSED } \\
\text { WIOE LEVEL EXCITATION } \\
\text { XI. HIMEVI, X? - GAMMAIMEY? }\end{array}$ \\
\hline 11 & $\begin{array}{l}\text { SECDND NEUTRON EMISSION } \\
X 1=\text { WIMEV } 1, X 2=\text { GAMMA(MEV) }\end{array}$ \\
\hline 15 & $\begin{array}{l}\text { DENS ITY AND TEMPERATURE DEPENDENT } \\
X 1=\text { DENS } I T Y, X Z=\text { TEMPERATURE (KEV, }\end{array}$ \\
\hline
\end{tabular}




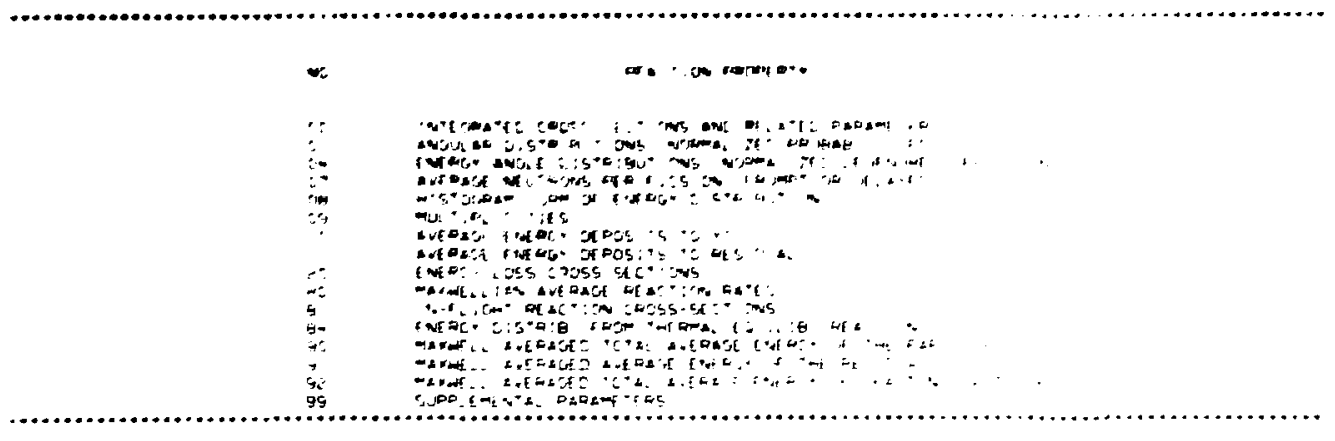

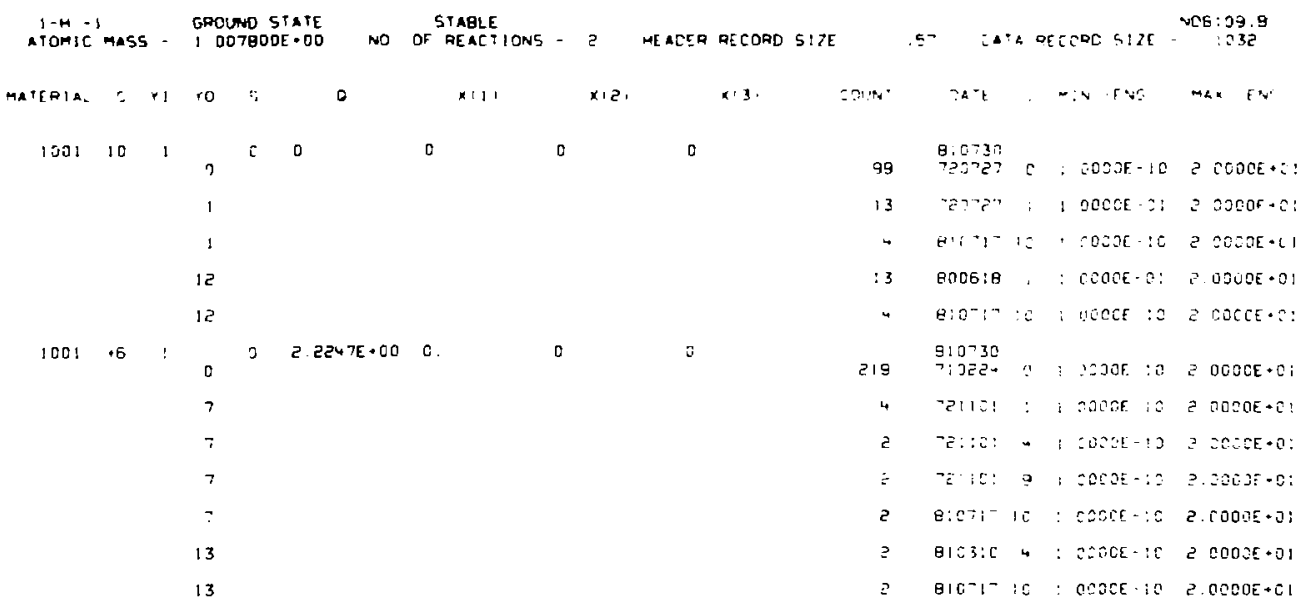



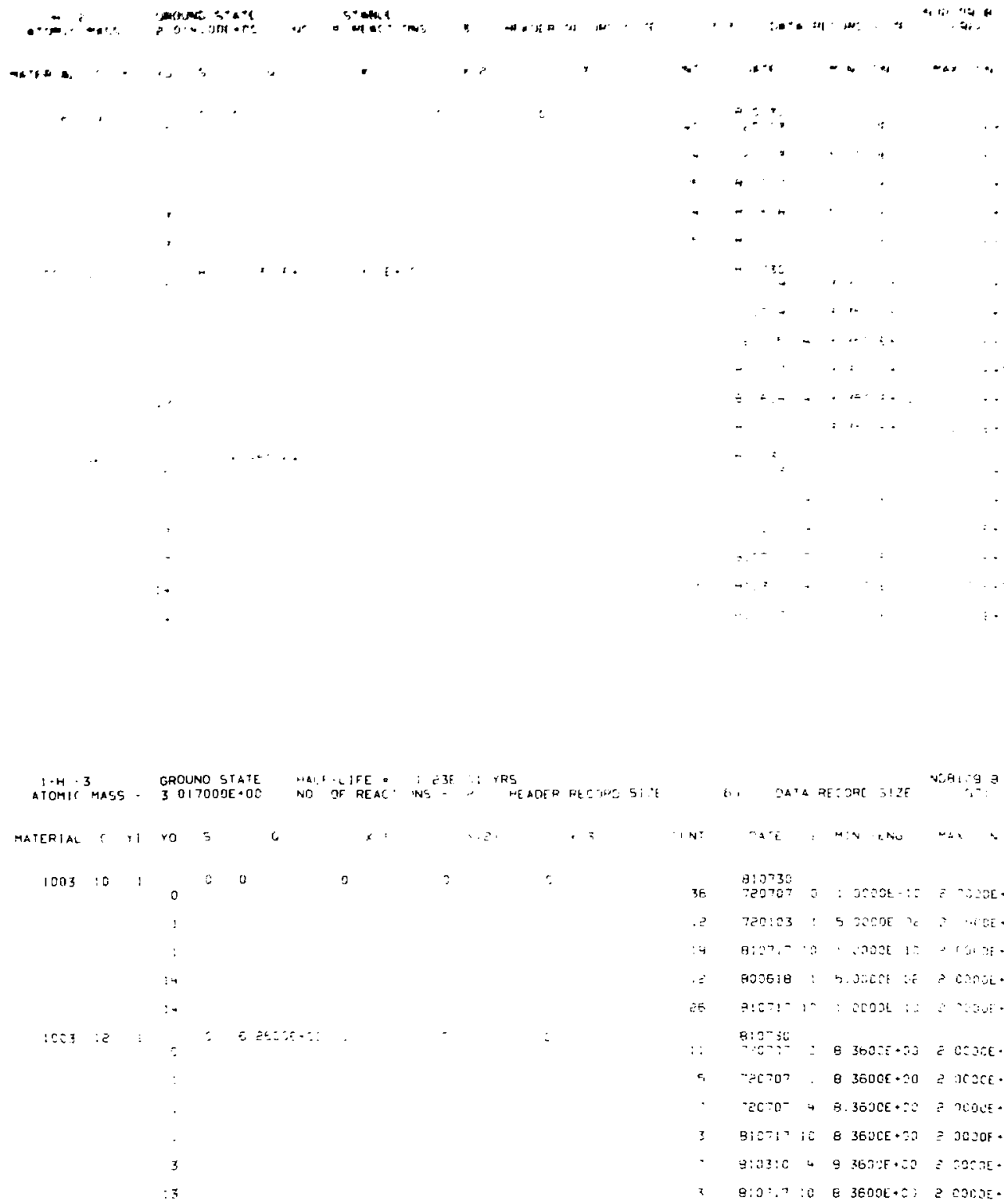


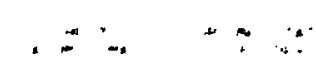

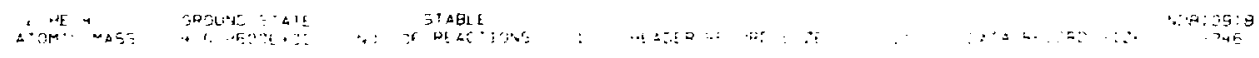

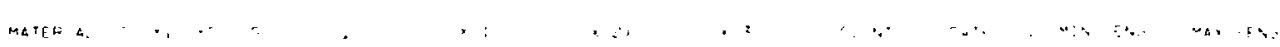

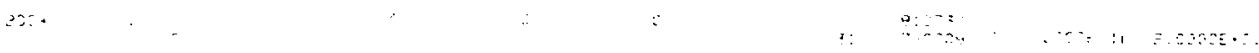

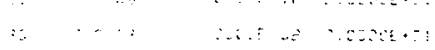

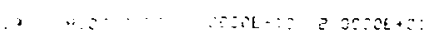

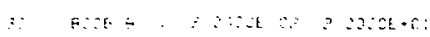

$$
\begin{aligned}
& \begin{array}{ll}
5 \\
5
\end{array}
\end{aligned}
$$

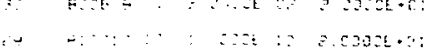

